\title{
Aleksander Jerzy Groszek: a pioneer in adsorption calorimetry
}

\author{
Władysław Rudziński · Erwin Lalik
}

Received: 26 September 2014/ Accepted: 28 September 2014/Published online: 8 October 2014

(C) The Author(s) 2014. This article is published with open access at Springerlink.com

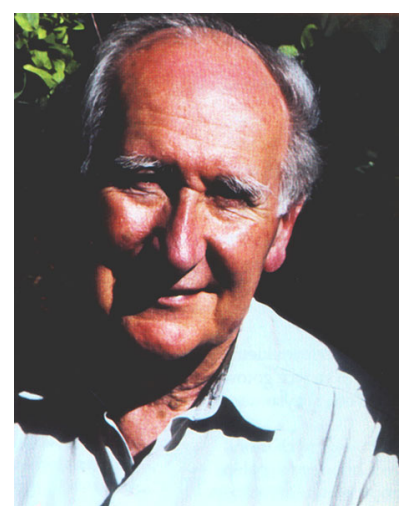

Aleksander Jerzy Groszek was born in Wilno, Poland (now Lithuania) on 17th February 1927. His education in Poland finished abruptly in Warsaw with the start of the Second World War. In 1939 his family moved to Rohatyn, before they were deported to Kazakhstan by the Russians in April 1940. Later in the War, after Germany marched on Russia, Aleksander applied to join the Free Polish Army and so he and his family became part of the evacuation of Polish troops from Russia. They were transferred to a displaced persons camp in Persia, where Aleksander was denied military service as he was too young, so he

\section{W. Rudziński ( $\square)$}

Department of Theoretical Chemistry, Maria Curie-Skłodowska University, Maria Curie-Skłodowska sq. 3, 20-031 Lublin, Poland

e-mail: rudzinsk@hermes.umcs.lublin.pl

\section{E. Lalik}

Jerzy Haber Institute of Catalysis and Surface Chemistry, Polish Academy of Science, ul. Niezapominajek 8, 30-239 Kraków, Poland completed his secondary education in Teheran before being moved to Beirut where he attended a French university and obtained national certificates of higher education leading to a 'License' diploma in Sciences. In 1947 his family moved to the UK, where, he was offered a place at London University to study Chemistry, graduating in 1951 .

That same year he took up a position as Chemist at Abril Corp. in Bridgend and continued studying, completing his M.Sc. in 1953, and his Doctorate in Chemistry in 1973. In 1953 he became a Research Chemist at National Benzole in Watford, and 4 years later he was offered a managerial position at British Petroleum in Sunbury, where he was based for 30 years. In 1979 Aleksander was promoted to Senior Research Associate at British Petroleum, and remained in this role until 1987. Whilst working at BP, in 1964 he set up Microscal Ltd.-a research and equipment manufacturing company, co-directed by his partner Charles Templer. In fact they met at a dinner party where they dreamed up a novel measuring device and scribbled-down their new Corporate Articles on a napkin. The formation of Microscal came to play a dominant role in both their lives.

His work at Microscal was primarily focused on research using his invention-the flow-through microcalorimeter to detect heat produced in reactions between either liquids or gases and solids. Throughout his career Aleksander's ability to synthesise, model, analyse and understand the structures and surfaces of materials, particularly carbons, marked him as a profound innovator and original thinker.

On his retirement from British Petroleum, Aleksander focused his scientific attention on microcalorimetric research. In addition to using his laboratory at Microscal in London, he embarked on collaboration with the Institute of Catalysis and Surface Chemistry of Polish Academy of Sciences in Krakow (Poland), effectively sponsoring a 
newly established laboratory of microcalorimetry by providing one of Microscal's newest gas flow-through instruments. This collaboration, in which Aleksander invested a lot of time and enthusiasm, started in 2001 and resulted in several discoveries and patents (Groszek et al. 2011; Groszek et al. 2012). However, Aleksander's approach to this co-operative venture was never strictly businesslike. For him it was an opportunity to share a part of his professional success with Poland, which he always considered his homeland.

That said, his professional and intellectual generosity characterised his activities at Microscal as well. He drove innovation in the instrumentation, embraced digital technology, reported his findings assiduously, often as Plenary speaker at conferences and he supported colleagues' endeavours and innovations. His wide life experience and scientific knowledge were invaluable. On the road he was a font of wisdom, entertaining and highly respected. In industry he had exceptional insight and was key to finding solutions to the many and varied problems we encountered.

An important part of the research, carried out both in Krakow and in London through this period was the investigation of anomalous thermal effects observed calorimetrically on interactions of materials containing atomic hydrogen with minute amounts of oxygen. These surprising effects caught Aleksander's imagination. The very accurate measurements enabled by the microcalorimeter of his design, plus a stroke of experimental ingenuity, made it possible to establish that the anomalously high heat evolutions (i.e., significantly larger than the energy of water formation) observed in these systems were beyond experimental error (Groszek et al. 2010; Groszek and Lalik 2011; Groszek 2013). These findings have been reported at conferences and in peer-reviewed journals. The nature of these effects, however, as well as a role played by the presence of noble gases like argon, remains undetermined. The legacy of his discoveries continues to be applied at the microcalorimetry laboratory in Krakow and in England at
Torftech Limited, a licensee of Microscal Two. These discoveries were patented and in 2011 he restructured the company to form Microscal Two, a collaboration between his son Martin Groszek and himself, purely concerned with the development of a new form of thermal energy system.

During Aleksander's career he successfully obtained about 50 British and U.S. patents and was responsible for at least 110 original publications. On the way he became a Fellow of the Royal Society of Chemistry and was awarded the DSc for his contribution to science. He was also a Fellow of the Institute of Petroleum in Britain, a company director, and a highly esteemed colleague who always had a twinkle in his blue eyes. He was a clever, creative and original scientist who was both understanding and generous.

Aleksander Jerzy Groszek died in Zakopane, Poland on 30th December 2013 aged 86. He is survived by his six children and his widow, Hanna.

Open Access This article is distributed under the terms of the Creative Commons Attribution License which permits any use, distribution, and reproduction in any medium, provided the original author(s) and the source are credited.

\section{References}

Groszek, A.J., Haber, J., Lalik, E.: Method for activating a catalyst. Patent Number: GB2430394 (2011)

Groszek, A.J., Haber, J., Lalik, E.: A method of activating of a composition. Patent Number: GB2453140 (2012)

Groszek, A.J., Lalik, E., Haber, J.: Heats of interaction of hydrogen with gold and platinum powders and its effect on the subsequent adsorptions of oxygen and noble gases. Appl. Surf. Sci. 256(17), 5498-5502 (2010)

Groszek, A.J., Lalik, E.: Effect of oxygen on the production of abnormally high heats of interaction with hydrogen chemisorbed on gold. Appl. Surf. Sci. 257(8), 3192-3195 (2011)

Groszek, A.J.: Abnormally high heat generation by transition metals interacting with hydrogen and oxygen molecules. Adsorption 19(2-4), 235-240 (2013) 